
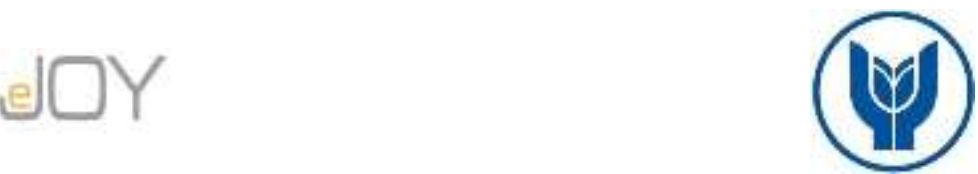

Beyaz Sipahi, B./ Journal of Yasar University, 2021, 16/61, 248-263

\title{
Hanehalkı Tasarruf Oranının Ekonomik ve Demografik Belirleyicileri: GMM Yaklaşımı
}

\section{Economic and Demographic Determinants of Household Savings Rate: GMM Approach}

\author{
Banu BEYAZ SİPAHİ, Tarsus Üniversitesi, Türkiye, banubeyazsipahi@tarsus.edu.tr
}

Orcid No: 0000-0002-5242-5049

\begin{abstract}
Öz: Hanehalkları tüketim, yatırım ve özellikle tasarruf yaparak ülkelerin ekonomik yapısını belirlemektedir. Tasarruf bir ekonominin temel dengesini sağlayan temel değişkendir. Ekonomik açıdan bireyler servetlerinin yanı sıra yaşamları boyunca gelir düzeylerine göre tasarruf yapma ĕgilimindedirler. Bu nedenle tasarruf oranlarını açıklamada en etkili faktörün gelir olduğu ekonomi kuramda yer alan gelir hipotezlerden ve literatür kapsamından kanıtlanmıştır. Bu çalışmada Türkiye İstatistik Kurumu (TÜIK) tarafindan yayınlanan Hanehalkı Bütçe Anketi2018 verileri kullanılarak tasarruf oranı ile kişi başına düşen gelir arasında eşanlı ilişki Genelleştirilmiş Momentler Yöntemi (GMM) ile incelenmiştir. Tasarruf oranı üzerinde kişi başına gelirin dolaylı etkisinin farklılık gösterdiği, kullanılan araç değişkenler kullanılarak ortaya konulmuştur. Yapılan analiz sonucuna göre en temel bulgu kişi başına düşen gelir artıkça tasarruf oranının artış göstermesidir. Hanehalkı tasarruf oranı \%13,9'dur. Ayrıca hanede çalışan kadın oranındaki artış ile oturulan konuta sahip olunması, yaşlı bağımlılık oranı, hanehalkı reisinin yaş dăğlımı tasarruf oranlarını pozitif etkilediği gözlenmektedir. Servet etkisi yapan ikinci konut, otomobil sahipliği gibi durumlar ise hanehalkı tasarruflarını negatif etkilemektedir
\end{abstract}

Anahtar Kelimeler: Tasarruf Oranı, Kişi Başı Gelir, İ̧̧ellik, Genelleştirilmiş Momentler Yöntemi

JEL Sinıflandırması:D1, C1,D6,J1

Abstract: Households determine that the economic structure of countries by consumption, investment and especially saving. The saving is the main variable that provides the basic balance of an economy. Economically, individuals tend to save in view of their income level throughout their lifetime as well as their wealth. For this reason the most effective factor in explaining saving rates is income. This demonstrate from the income hypotheses in the economic theory and literature. In this study, household budget survey-2018 data that released by Turkey Statistical Institute (TurkStat) are used. The simultaneous relationship between saving rate and per capita income are analyzed by Generalized Moments Method (GMM). The indirect effect of per capita income on the saving rate demonstrates that difference by using the instrumental variables. According to the result of the analysis, the basic finding is that the saving rate increases as the per capita income increases. Household saving rate is $13.9 \%$. In addition, it is observed that the increase in ratio of women working in the household, ownership of a house, the elderly dependency ratio, the age distribution of the household head positively affect saving rates. Wealth effect such as second home and car ownership negatively affect household saving.

Keywords: Saving Rate, Per Capita Income, Endogeneity, Generalized Method Moments

JEL Classification:D1, C1,D6,J1

\section{Giriş}

İktisat teorisinde klasik okuldan günümüze kadar tasarruf en çok tartışılan konulardan biridir. En genel tanımıyla tasarruflar, milli gelirin harcanabilir gelir kısmından bir yıl içinde tüketime ayrılmayan kısmını ifade etmektedir. Harcanabilir gelir arttıkça tüketimde artış gösterir ancak bu artış azalan bir eğilimle gerçekleşmektedir. Bu yüzden gelir arttıkça tüketimin payı azalırken tasarrufun payı artar (McConnell ve Brue,2008). Kapalı bir ekonomi için, tasarruflar toplam yatırımlara veya sermaye oluşumuna eşittir. Yurtiçi tasarruflar bir ülkenin gelişmişlik düzeyini göstermektedir. Açık bir ekonomi için, cari işlemler dengesi fazlalık veya açık verebileceğinden 
yurtiçi tasarruflar yurtiçi yatırımları aşabilir ya da gerisinde kalabilir. Yurtiçi tasarruflar hanehalkı tasarrufu, mali olan ve olmayan şirket tasarrufları ve devlet tasarrufları olarak dört ana bileşenden oluşmaktadır (Narinç ve Küçükönder, 2020). Ülkelerin yurtiçi tasarruflarını artırmasının en temel yolu hanehalkı tasarruflarının artırılmasından geçmektedir. Hanehalkı tasarrufu hanehalkının harcanabilir gelirinden tüketilmeyen kısmını oluşturur. Gelişmiş ve gelişmekte olan ülkelerde hanehalkı tasarruflarının belirleyicilerini tespit etmek önemlidir.

Bu çalışmada TÜİK-Hanehalkı Bütçe Anketi (HBA-2018) üzerinden yola çıkılarak özel kesim tasarrufların belirleyicisi olan hanehalkı tasarruf oranını etkileyen faktörler hangi düzeyde etkilediği tüm hanehalkını kapsayacak şekilde incelenmiştir. Tasarrufu etkileyen faktörleri çeşitli alt gruplar altında incelemek politika oluşturmak için önemlidir.

Çalışma beş bölümden oluşmaktadır. Çalışmanın ikinci kısmında Türkiye'de hanehalkının tasarruf davranışları ve hanehalkı tasarruf oranlarının belirleyicilerine yer verilmiştir. Üçüncü kısımda analiz aşamasında kullanılan veri seti, metodolojisi ve tanımlayıcı istatistikler verilmiştir. Dördüncü kısımda ise model tahmin sonuçları verilmiş ve son bölümde ise sonuç ve önerilere yer verilmiştir.

\section{Tasarruf Davranışları ve Hanehalkı Tasarruf Oranlarının Belirleyicileri}

Hanehalkı, devlet ve işletmeler gibi ekonomik birimler gelirlerinin tamamını tüketmek yerine yaşam koşullarını göz önünde bulundurarak gelirlerinin bir kısmını tasarrufa ve bir kısmını da yatırıma ayırmaktadırlar. Tasarruf sahibi bireylerin yatırım yapma açısından iki amacı bulunmaktadır. İlki; yapmış oldukları tasarrufların değer kaybetmemesini sağlamak, ikinci olaraktan tasarruflardan devamlı ve makul düzeyde gelir elde etmektir (Bozkuş ve Üçdoğruk, 2007). Yatırım tasarruf eşitliği varsayımı altında gelir, tüketim ile tasarruf arasında paylaştırılmaktadır. Tüketim ve tasarruflar üzerinde bireylerin isteklerinin etkisi yüksektir. Bununla birlikte tasarruf ve dolaylı olarak tüketim bazı değişkenlerden etkilenmekte ve etkilemektedir (Bagley ve Perdew, 1951). Bu aşamada ilk yapılması gereken tasarruf davranışını etkileyen ve tasarruf davranışından etkilenen değişkenleri tespit etmek gerekir (Loayza ve vd., 2000).

Ekonomide tüketim kuramına göre tasarruf davranışlarını ele alan ilk çalışma Fisher (1930) aittir. Fisher'e göre tüketiciler tasarruf veya borçlanma yoluyla tüketim kararı verebilmektedir. Optimizasyon ilkesine göre bireyler dönemler arası tasarruf düzeylerini belirlemektedirler. Fisher modelinin en çok eleştirilen tarafı gerçek hayatta bireylerin likidite kısıtıyla karşı karşıya kalabilme ihtimallerinden dolayı, gerçek hayatta bireylerin gelecekte elde edecekleri gelir karşılığında borçlanamamasıdır (Mankiw, 1992). Bununla birlikte Keynes’in 1936 'da “Mutlak 
Gelir Hipotezi ${ }^{1}$ " tasarruf davranışını açıklayan ilk temel çalışmadır. Tasarruf kuramına diğer önemli bir katkı ise Duesenberry (1949) tarafından ortaya atılan 'Nispi Gelir Hipotezi”' dir. Bu hipotezin Keynesyen'nin hipotezinden farklı kılan tarafı tüketimin gelir düzeyindeki düşüş seviyesi ile aynı olmadığını, tasarrufu azaltarak tüketimi koruduğu yöndedir (Barrett, 1975). Tasarruf kuramının gelişmesinde önemli bir diğer hipotez de Modiglian ve Brumberg (1954) tarafından gerçekleştirilen “Yaşam Boyu Gelir Hipotezi” 'dir. Bu hipoteze göre de tasarruf ve tüketim kararı verirken uzun dönem dikkate alınmıştır. Yaşamın farklı dönemlerinde gelir değişkenliğine göre tasarruf davranışı şekil almaktadır (Sachs ve Larrain, 1993). Tasarruf davranışını açıklayan diğer bir hipotez ise Friedman'ın (1957) “Sürekli Gelir Hipotezi”’dir. Bu hipotezde de cari gelir yerine uzun dönemi kapsayan sürekli gelire dayanmaktadır. Tasarruf kararları gelecekteki gelire göre belirlenmektedir. Gelecekteki gelir ile tasarruf arasında ters yönlü bir ilişki söz konusudur (Ünsal, 2005).

Tasarruf oranlarını açıklamada en etkili faktörün gelir olduğu ekonomi kuramda yer alan gelir hipotezlerden ve literatür kapsamından kanıtlanmıştır. Gelişmekte olan ülkelerde çalışmalar daha çok sürekli gelir hipotezine odaklanmıştır. Yaşam boyu gelir hipotezinin öngörüsüne göre de gelirin yüksek olduğu dönemlerde tasarruflar artmakta, düşük seyrettiği dönemlerde tasarruflar azalmaktadır. Ancak gelir artışının kalıcı olduğu zaman tüketim artışı gelir artışının önüne geçerse tasarruflarda düşüşe sebep olabilmektedir (Tobin, 1967).

Tasarruf konusu 1930'ların ortalarına kadar temel düzeyde ele alınmış olsa da literatürde mikro ve makro düzeyde farklı açılardan ele alınan bir konudur. Ekonomik literatürde tasarrufun belirleyicilerini ele alan birçok çalışma bulunmaktadır (Aka ve Arıcan, 2019). Browning (1995) çalışmasında hanelerin veya bireylerin tasarruf etmesini etkileyen faktörlerin mikro düzeyde olduğunu vurgulamıştır. Mikro seviyede tasarruf üzerine hemen hemen bütün çalışmalarda en önemli belirleyici gelir'dir. Tasarruf sahipleri karar alma aşamasında etkilendiği bazı faktörler bulunmaktadır. Bunlar kişisel, finansal ve çevresel faktörler olarak gruplayabiliriz. Kişisel faktörler içerisinde tasarruf sahibinin yaşam biçimi, cinsiyeti, yaşı, eğitim düzeyi, geliri gibi sosyo ve ekonomik değişkenler yer alır. Finansal faktörler yönünden ise enflasyon, faiz gibi ekonomik trendler tasarruf sahiplerinin karar alma sürecini etkilemektedir. Çevresel faktör grubunda ise tasarruf yapan kişinin bulunduğu ortam ve çevre koşulları yer almaktadır. Tasarruf kararları alınırken bireyler dolaylı veya doğrudan sosyoekonomik koşullardan etkilenirler.

\footnotetext{
${ }^{1} \mathrm{Bu}$ hipoteze göre gelir düzeyi düşük aileler gelirlerinin büyük bir kısmını tüketime ayırırken, yüksek gelir grubuna sahip haneler ise daha fazla tasarrufa ayırmaktadır.
} 
$\mathrm{Bu}$ çalışmanın amacı hanehalkı tasarruf oranını belirleyen etkenler ve tercihler olduğu için literatür kapsamında bu yönde yapılan ve bu çalışmaya 1şık tutan çeşitli çalışmaların yöntem ve bulguları incelenmiştir. Türkiye'de tasarruf tercihlerinin belirleyicileri ile ilgili pek çok çalışma mevcuttur. Ancak tasarruf oranının gelir ile olan ilişkisini ele alan çalışma sayısı sınırlıdır. Genel olarak uygulama yöntemi olarak daha çok kategorilendirilmiş tasarruf oranını ele alan logit ve multinominal modeller tercih edilmiştir (Narinç ve Küçükönder,2020; Barış ve Çiftçi, 2018; Şengür ve Taban, 2016; Temel Nalın, 2013; Çolak ve Öztürkler, 2012; Tunalı ve Tatoğlu, 2010; Bozkuş ve Üçdoğruk, 2007). Chen ve ark.(2019) çalışmasında Çin'de 2015 yılına ait hanehalkı anket verilerinden birden fazla ev sahibi olmanın IV-Tobit Regresyon model ile riskli ve risksiz portföy seçimine etkileri incelemiştir. Hamarat ve Özen (2015) çalışmasında kanonik regresyon yöntemi kullanmış ve tasarruf ile yatırım arasında ilişki incelemiştir. Ioannis Kostakis (2013) çalışmasında OLS, 2SLS ve Tobit model yöntemi ile tasarruf üzerine en önemli faktörün gelir düzeyi olduğunu ortaya koymuştur. Gandelman (2014) çalışmasında harcama ve gelir anketi kullanarak 9 Latin Amerikan ülkesi için yaş, gelir ve eğitim düzeyine göre tasarruf davranışı analiz etmiştir. Rehman ve ark. (2011) çalışmasında Pakistan için gelir gruplarına göre tasarruf belirleyicilerini araştırmıştır. Belirleyici olarak hanehalkı reisinin eğitim düzeyi, çocukların eğitim düzeyi, yaş, medeni durum, hanehalkı reisinin ödemesi gereken borçlar, evin değeri gibi değişkenler kullanılmıştır. Rijckeghem (2010) çalışmasında Türkiye için 2004-2008 HBA verileri kullanarak incelemiştir. Çalışmada hanehalkı tasarrufları üzerinde etkili hanenin demografik yapısı araç değişken yöntemiyle hesaplanan gelir, eğitim, sosyal güvence, istihdam, hanenin beklenen sağlık harcaması riski, ev sahipliği, faiz geliri sahipliği değişkenleri kullanılmıştır.

$\mathrm{Bu}$ çalışmanın diğer çalışmalardan farkı tasarruf ile gelir arasındaki ilişkinin yönünü araç değişken yöntemi kullanılarak diğer tasarruf belirleyicileri ile birlikte analiz etmektir. Hızlı gelişen ülkelerde toplam tasarruf oranı ve gelir artışları birbiri ile ilişkili olarak artmaktadır (Modigliani,1986; Collins,1989). Ancak sürekli gelir hipotezi gelecekteki yüksek gelir beklentisine karşı insanların tasarruflarda azalmaya sebep olacağını belirtmiştir. Bir biriyle çelişen bu durumda ekonometrik analiz sonuçlarına bakmak gerekecektir. Bu bağlamda bu çalışmada gelir artışı tasarruf oranındaki artışa sebep olabilmektedir. Bununla birlikte aslında tasarruf oranı artışı tasarruf sahibi bireylerin yatırım yapma amacına bağlı olarak tasarrufların değer kazanmasını ve gelir getirmesini amaçlar. Burada içsellik sorunu olabileceğinden çalışmada bu sorunun ele alınması gerektiği düşünülmüştür. 


\section{Veri ve Yöntem}

\subsection{Veri Seçimi}

Türkiye'de mikro düzeyde tasarruf çalışmalarının çoğunun veri seti TÜİK-Hanehalkı Bütçe Anket (HBA) tarafından sağlanmaktadır. Bu çalışmada veriler son yayınlanan TÜİK-2018 Hanehalkı bütçe anket (HBA) veri seti içerisinde yer alan "Hane Değişkenleri” ile "Fert Değişkenleri” kısmında hane halkı ve hane halkı reisine yöneltilen sorulardan faydalanılarak oluşturulmuştur.

Hanehalkı tasarruflarını etkileyen faktörler tüm hanehalkını ne ölçüde etkileyeceği ele alınmıştır. Analiz aşamasında etkili olan faktörleri belirlemede literatürde yapılan çalışmalar göz önünde bulundurulmuştur. Model sonuçlarının tutarlılığı için örneklemde hanehalkı reisi 20 yaşından küçük olan haneler ve şüpheli gözlemler örneklemden çıkarılmıştır. HBA-2018 verileri kapsamına hanehalkı reisi çalışan ve işsiz olan tüm hanehalkları dahil edilmiştir. Hanehalkı tasarrufları üzerinde etkili olan temel faktörlere ilişkin yapılan analizde kullanılan değişkenler; bağımlı değişken olan tasarruf oranı hanelerin yıllık gelirinden harcamaları çıkardıktan sonra gelire oranı şeklinde hesaplanmıştır. Negatif tasarruf oranına sahip olan 5 hanenin yanlış beyanda bulunacağı için özellikle düşük gelirli hanelerde sosyal yardım alanların yardımları kaybetmemek için yanlış gelir beyanında bulunmuş olacağı düşünüldüğünden bu değişkenler örneklemden çıkarılmıştır. Analiz için gerekli düzenlemeler yapıldıktan sonra en son olarak 11803 hane analize tabi tutulmuştur.

Modelde kullanılan açıklayıcı değişkenler; hanelerin yıllık kullanabilir gelirinin OECD ölçeğine göre hesaplanmış eşdeğer hane büyüklüğüne ${ }^{2}$ oranından elde edilen kişi başına gelir, hane tipi, hanehalkı reisinin çalışma durumu, hanenin genç bağımlılık oranı (hanede 14 yaş ve altı bireylerin hanehalkı büyüklüğüne oranı) ve yaşlı bağımlılık oranı (hanede 65 yaş ve üstü bireylerin hanehalk1 büyüklüğüne oran1), hanehalk1 reisinin en son mezun olduğu eğitim düzeyi, yaşı ve medeni durumu, hanelerin otomobil sahipliği, birinci ve ikinci konut sahipliği ve arsa sahipliği, sıcak su sahipliği ve kişi başına oda sayısı (hanedeki oda sayısının OECD eşdeğer ölçeğine oranı) olarak belirlenmiştir. Çalışmada kullanılan değişkenler ile ilgili tanımlayıcı istatistikler ile bu değişkenlerin açıklamaları Tablo-1'de yer almaktadır.

\footnotetext{
${ }^{2}$ Hanedeki ilk yetişkin için 1, 14 ve daha yukarı yaştaki fertler için $0.5,14$ yaşından küçük fertler için 0.3 değerleri dikkate alınarak hesaplanan hanehalkı büyüklüğüdür.
} 
Tablo 1. Modelde Kullanılan Değişkenlerin Tanımlayıcı İstatistikleri

\begin{tabular}{|c|c|}
\hline Değişkenler & Yüzde Değer \% \\
\hline HHT1-Tek kişilik hanehalkı & 9.7 \\
\hline HHT 2-Eşlerden oluşan çekirdek aile & 18.8 \\
\hline HHT 3-Eş ve çocuktan oluşan çekirdek aile & 49.8 \\
\hline HHT 4-Tek ebeveyn ve çocuktan oluşan çekirdek aile & 7.1 \\
\hline HHT 5-En az bir çekirdek aile ve diğer kişilerden oluşan hanehalkı & 1.5 \\
\hline HHT 6-Çekirdek ailede bulunmayan birden fazla kişiden oluşan hanehalkı* & 13 \\
\hline KS-1 Konut Sahipliği(Eğer Evet ise $=1$ ) & 60.8 \\
\hline KS-2 İkinci konut Sahipliği (Eğer Evet ise=1) & 8.4 \\
\hline Apartman Sahipliği(Eğger Evet ise=1) & 35.4 \\
\hline Otomobil Sahipliği (Eğer Evet ise=1) & 43.2 \\
\hline HHR-C Hanehalk1 reisinin cinsiyeti ((Erkek=1, Kadın=0) & 84.6 \\
\hline E1-HHR İlkokul ve altı eğitim düzeyine sahip (Eğer Evet ise=1) & 53.3 \\
\hline E2-HHR İlköğretim ve ortaokul eğitim düzeyine sahip (Eğer Evet ise=1) & 14.5 \\
\hline E3- HHR Lise eğitim düzeyine sahip (Eğer Evet ise=1) & 17.2 \\
\hline E4-HHR Üniversite ve üstü eğitim düzeyine sahip (Eğer Evet ise=1)* & 15 \\
\hline M1-HHR Bekar & 4 \\
\hline M2-HHR Evli & 81.7 \\
\hline M3- HHR-Boşandı & 4.4 \\
\hline M4- HHR Eşi Öldü* & 9.9 \\
\hline Y1- HHR 21-35 yaş grubu & 16.4 \\
\hline
\end{tabular}




\begin{tabular}{|c|c|}
\hline Y2-HHR 36-50 yaş grubu* & 35.1 \\
\hline Y3-HHR 51-64 yaş grubu & 31.5 \\
\hline Y4-HHR 65 yaş ve üstü yaş grubu & 17 \\
\hline HHR-ÇD (Eğer çalışıyor ise=1) & 67 \\
\hline Sıcak su sahipliği(Eğer Evet ise=1) & 94.1 \\
\hline Sürekli ve Kategorik Değişkenler & Ortalama \\
\hline \multirow[t]{3}{*}{ Tasarruf Oranı } & 0.917 \\
\hline & $(0.049)$ \\
\hline & 56814.74 \\
\hline \multirow[t]{2}{*}{ Gelir (OECD ölçeğine göre hesaplanmış kişi başına düşen gelir) } & $(55087.692)$ \\
\hline & 0.84 \\
\hline \multirow[t]{2}{*}{ Genç bağımlılık oranı } & $(1.162)$ \\
\hline & 0.33 \\
\hline \multirow[t]{2}{*}{ Yaşlı bağımlılık oranı } & $(0.624)$ \\
\hline & 0.39 \\
\hline \multirow[t]{2}{*}{ Hanede çalışan kadın sayısı } & $(0.563)$ \\
\hline & 1.912 \\
\hline Kişi başına oda sayısı & $(0.76)$ \\
\hline
\end{tabular}

Not: HHT: Hanehalkı tipi; HHR:Hanehalkı reisi HHR-ÇD: Hanehalkı reisinin çalışma durumunu ifade etmektedir. * modelde kullanılan referans değişkenleri ifade etmektedir. Sürekli ve kategorik değişkenlerde parantez içerisinde standart sapma değerleri verilmiştir.

\subsection{Yöntem}

Yapılan çalışmalarda daha çok tasarruf oranını etkileyen faktörler incelenirken gelirin etkisi tek yönlü olarak ele alınmıştır. Oysa bu iki değişken arasındaki en büyük problemin içsellik sorununun olup olmamasıdır. Bu çalışmada ciddi ölçüm hatalarına sebep olacağı düşünülen gelirin içsellik probleminden ötürü gelir değişkeni modele direk dahil edilmemiş ve geliri etkileyen tasarruf oranını etkilemeyen araç değişken kullanılmıştır. Araç değişken seçiminde önemli bir noktada kullanılan araç değişken sayısının içsel değişken sayısına eşit veya daha fazla olması gerekmektedir (Gujarati ve Porter, 2009). Bu bağlamda modelde kullanılan araç değişken olarak kişi başına oda sayısı ve hanenin sıcak su erişim bilgileri kullanılmıştır. İçsellik problemi literatürde daha çok ad hoc çözümü ve araç değişken (IV) yöntemi ile kaldırılmaktadır. En yaygın olan yöntem IV yöntemidir. IV tahmincileri, en küçük kareler ile 
kıyaslandığında önemli etkinlik kaybına yol açmaktadır. İki aşamalı en küçük kareler yöntemi (2AEKK) sonuçlarının etkin olabilmesi için hata teriminin sabit varyanslı ve otokorelasyonsuz olması gerekmektedir. Oysa Genelleştirilmiş Moment Metodunda (GMM) ise böyle bir ön koşul bulunmamakta ve GMM yöntemi hata terimini minimize edebilmektedir. Modellerde seçilen araç değişkenleri birden fazla olduğu için GMM yöntemi hata terimlerinin düzeltmesinde daha etkin bir yöntem olacaktır. Standart araç değişken yöntemi GMM tahmincisinin özel bir durumudur. Araç değişkenlerin $(Z)$ dışsal olduğu kabul edilir. $E\left(Z_{i} u_{i}\right)=$ 0. Burada, X ve Z, sirasiyla, nxK ve nxL tipinde birer tahmin matrisidir (Beyaz Sipahi, 2020).

$g_{i}(\hat{\beta})=Z_{i}^{\prime} \widehat{u_{\imath}}=Z_{i}^{\prime}\left(y_{i}-X_{i} \widehat{\beta}\right)$

Denklem (1)'de $g_{i}$, Lx1 boyutlu olmak üzere, $\mathrm{L}$ araç değişkenleri L tane momentin veri setini oluşturur. Z'nin dışsal olması için, L tane moment koşulunun sağlanması durumunda, $\beta$ 'nın gerçek değeri için $E\left(g_{i}(\beta)\right)=0$ koşulu sağlanmalıdır. Eğer tahmin edilecek model tam belirlenmiş ise, yani $\mathrm{L}=\mathrm{K}$ ise, GMM tahmincisi IV tahmincisidir. Ancak $\mathrm{L}>\mathrm{K}$ ise, bütün $\mathrm{L}$ örnek moment şartlarını ve $\beta$ tahmincisi bulmak mümkün değildir. Bu durumda, LxL tipinde bir W ağırlıklı matrisi alınır ve GMM modelin tahmin edicisi aşağıdaki gibi ifade edilir.

$\widehat{\beta_{G M M}}=\left(X^{\prime} Z W Z^{\prime} X\right)^{-1} X^{\prime} Z W Z^{\prime} y$

GMM tahmincisi minimizasyon sebebiyle, oransal sabitten farklı olan W ağırlık matrisi ile eş değerdir. Ayrıca, W ağırlık matrisinin seçimine bağlı olarak birden fazla GMM tahmincisi elde edilir. Burada en uygun ağırlık matrisinin seçilmesi gerekmektedir (Baum ve ark. 2003). Model seçimini GMM olarak belirlendikten sonra bu çalışmanın modeli aşağıdaki eşitliklerle gösterilmiştir.

Kişi Baş̧ı Gelir $=\alpha_{1}+\beta_{1} x+\gamma Z+\varepsilon_{1}$

Tasarruf Oranı $=\alpha+\beta_{2}$ kişi başına gelir $+\gamma X_{i}+\varepsilon_{2}$

$E\left(\varepsilon_{1}\right)=E\left(\varepsilon_{2}\right)=0 \quad \operatorname{Var}\left(\varepsilon_{1}\right)=\operatorname{Var}\left(\varepsilon_{2}\right)=1 \quad \operatorname{Cov}\left(\varepsilon_{1}, \varepsilon_{2}\right)=\boldsymbol{\rho}$

İlk olarak eşitlik 3'deki denklemde x kişi başına düşen geliri etkileyen hanehalkı değişkenleri ve hanehalkı reisinin özelliklerini ifade eden değişkenleri, $Z$ araç değişkenleri göstermektedir. Araç değişken geliri etkileyen fakat $\varepsilon_{2}$ ile ilişkili olmayan değiş̧kenlerdir. Eşitlik 4 'ise tasarruf oranı üzerinde gelirin etkisine bakılmıştır. Tasarruf oranı üzerinde gelirin dolaylı etkisi 
önemlidir. Eşitlikte $X$ değişkenleri ise tasarruf oranını etkileyen değişkenlerdir. Modelde $\beta_{2}$ katsayısı diğer değişkenlere bağlı tasarruf oranı koşulu üzerinde gelirin direk etkisini göstermektedir. Bu eşitlikte bazı değişkenler gelir tarafından etkilenecektir. Gelir ve tasarruf oranı eşitliğinde hata terimleri arasında korelasyon $\rho$ dur. Eğer bu iki değişken arasında içsellik sorununu dikkate alınmazsa yanlılık sorunu ortaya çıkar. Bu nedenle gelirin içselliğini Hausman içsellik testinden geçirilmesi gerekmektedir. Eğer sıfırdan farklı ise, tasarruf oranı ve gelir içseldir. Bu durumda modelde içsellik kontrolü için geliri etkileyen uygun araç değişkeni Z belirlemek gerekmektedir (Cameron ve Trivedi, 2009).

\section{Tahmin Sonuçları}

Model için sıcak su sahipliği ve OECD ölçeğine göre hesaplanmış kişi başına düşen oda sayısı uygun araç değişkeni olarak belirlenmiş ve modelde kullanılmıştır ${ }^{3}$. Bu veri seti içerisinde seçilen bu araç değişkenler kişi başına düşen gelir için konutun kullanım alanı ve imkânları önemli bir faktör olabilir. Tasarruf oranı ile gelir arasında içsellik problemi tablo 2'de yer alan GMM C istatistiği ki-kare değeri ile gösterilmiştir. Kişi başına düşen gelir dışsaldır şeklinde kurulan hipotez reddedilerek tasarruf oranı ile kişi başına düşen gelir arasında içsellik problemi olduğu görülmüştür. Bu iki değişken arasında nedensel ilişki olduğuna karar verilmiştir. Uygun araç değişken sayısı içsel değişken sayısından fazla olduğu için over identified (aşırı özdeşleştirilmiş) özelliğini sağlanmış oluyor. Bunun için Hensen's J ki-kare test istatistiği ile “aşırı özdeşleştirilmiş kısıtı vardır” boş hipotezi test edilmiş ve seçilen araç değişkenlerin uygun olduğu kanısına varılmıştır (Bakınız Tablo-2).

Tablo 2. Model Tahmin Sonuçları (GMM-2018)

\begin{tabular}{|c|c|c|c|c|c|c|}
\hline \multirow[t]{2}{*}{ Açıklayıcı Değişkenler } & \multicolumn{3}{|c|}{$\begin{array}{l}\text { Bağımlı Değişken Kişi } \\
\text { başına Gelir (İlk Aşama } \\
\text { Regresyon) }\end{array}$} & \multicolumn{3}{|c|}{ Bağımlı Değişken Tasarruf Oranı } \\
\hline & Katsayı & S. Hata & T değeri & Katsayı & S. Hata & $\mathbf{Z}$ değeri \\
\hline Kişi Başı Gelir^^ & - & - & - & 0.00000022 & 0.00118 & $1.85 * * *$ \\
\hline Sabit Terim & 15150.29 & 2556.07 & $5.93 *$ & 0.93 & 0.01 & $148.52 *$ \\
\hline
\end{tabular}

${ }^{3} \mathrm{GMM}$ model Stata-14 paket programı kullanılarak uygulanmıştır. Bu seçilen araç değişkeneler kişi başına düşen gelir üzerinde etkili ancak tasarruf oranı üzerinde etkili olmayan değişkenler olarak belirlenmiştir. Seçilen bu araç değişkenlerinin kişi başına gelir değişkeninin hata terimi ile ilişkili olup olmadığı test edilmesi gerekmektedir. Bu nedenle GMM modelde hesaplanan Hensen's J ki-kare test değeri seçilen araç değişkenin uygunluğunu sinamaktadır. 


\begin{tabular}{|c|c|c|c|c|c|c|}
\hline $\begin{array}{l}\text { HHT1-Tek kişilik } \\
\text { hanehalk1 }\end{array}$ & -3204.40 & 1453.34 & $-2.20^{* *}$ & -0.015 & 0.00378 & $-3.89 *$ \\
\hline $\begin{array}{l}\text { HHT 2-Eşlerden oluşan } \\
\text { çekirdek aile }\end{array}$ & -5895.61 & 921.58 & $-6.40^{*}$ & -0.008 & 0.00172 & $-4.71 *$ \\
\hline $\begin{array}{l}\text { HHT 3-Eş ve çocuktan } \\
\text { oluşan çekirdek aile }\end{array}$ & 1223.00 & 639.10 & $1.91 * * *$ & -0.005 & 0.00156 & $-3.35^{*}$ \\
\hline $\begin{array}{l}\text { HHT 4-Tek ebeveyn ve } \\
\text { çocuktan oluşan çekirdek } \\
\text { aile }\end{array}$ & -2523.22 & 1104.27 & $-2.28 * *$ & -0.007 & 0.00314 & $-2.21 * *$ \\
\hline $\begin{array}{l}\text { HHT 5-En az bir çekirdek } \\
\text { aile ve diğer kişilerden } \\
\text { oluşan hanehalkı }\end{array}$ & -4125.18 & 1763.47 & $-2.34 * *$ & -0.005 & 0.00413 & -1.15 \\
\hline $\begin{array}{l}\text { KS-1 Konut sahipliği(Eğer } \\
\text { Evet ise=1) }\end{array}$ & 90.31 & 467.92 & 0.19 & 0.005 & 0.00118 & $3.97 *$ \\
\hline $\begin{array}{l}\text { KS-2 İkinci konut sahipliği } \\
\text { (Eğer Evet ise }=1 \text { ) }\end{array}$ & 6649.47 & 1268.16 & $5.24 *$ & -0.001 & 0.00201 & -0.63 \\
\hline $\begin{array}{l}\text { Apartman Sahipliği(Ĕger } \\
\text { Evet ise=1) }\end{array}$ & 8163.89 & 497.59 & $16.41^{*}$ & 0.003 & 0.00151 & $2.31 * *$ \\
\hline $\begin{array}{l}\text { Otomobil sahipliği (Eğer } \\
\text { Evet ise=1) }\end{array}$ & 6733.55 & 587.24 & $11.47 *$ & -0.014 & 0.00125 & $-11.52^{*}$ \\
\hline $\begin{array}{l}\text { HHR-C Hanehalkı reisinin } \\
\text { cinsiyeti ((Erkek=1, } \\
\text { Kadın=0) }\end{array}$ & 1795.77 & 972.00 & $1.85^{* * *}$ & -0.004 & 0.00265 & -1.39 \\
\hline $\begin{array}{l}\text { E1-HHR İlkokul ve altı } \\
\text { eğitim düzeyine sahip } \\
(\text { Eğer Evet ise=1) }\end{array}$ & -23024.89 & 1049.31 & $-21.94 *$ & -0.007 & 0.00350 & $-2.10 * *$ \\
\hline $\begin{array}{l}\text { E2-HHR İlköğretim ve } \\
\text { ortaokul eğitim düzeyine } \\
\text { sahip (Eğer Evet ise=1) }\end{array}$ & -20223.85 & 1108.81 & $-18.24 *$ & -0.005 & 0.00319 & $-1.69 * * *$ \\
\hline
\end{tabular}




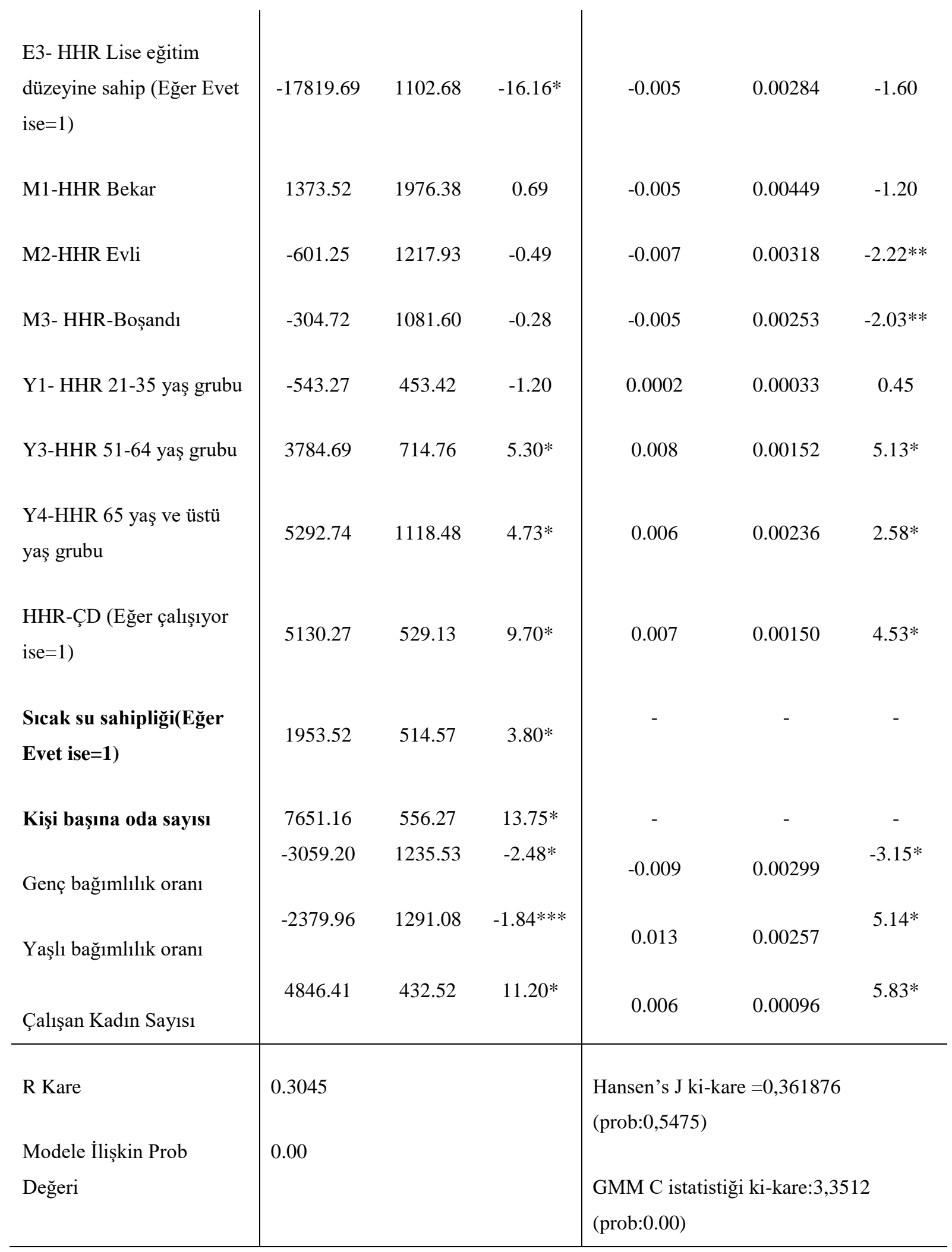

Not:^ OECD ölçeğine göre hesaplanmış kişi başına düşen geliri ifade etmektedir. Tabloda $\% 1, \% 5$ ve $\% 10$ anlamlılık düzeylerinde istatistiksel olarak anlamlı bulunan parametreler sirasıyla $*, * *$ ve $* * *$ işareti ile gösterilmiştir.

Model tahmin sonuçları tablo 2'de yer almaktadır. 2018 yılı için kurulan GMM model analiz sonuçlarına göre modele dâhil edilen değişkenlerin hemen hepsinin literatür 
doğrultusunda beklenen işarete ve yöne sahip olduğu görülmektedir. Kurulan model 23 açıklayıcı değişkenden ve 2 araç değişkenden oluşmaktadır. GMM modelde ilk aşama regresyon modelinde kişi başına gelir üzerinde etkili olan değişkenlerin istatistiksel olarak anlamlılık düzeyleri gösterilmiştir. Modelde araç değişken olarak seçilen kişi başına oda sayısı ve hanelerin sıcak su sahipliği ile kişi başına düşen gelir arasında pozitif ilişkiye rastlanmıştır.

Modelin bir bütün olarak anlamlılığını test eden p değerine göre (prob değeri 0.00) modeli istatistiki olarak anlamlı bulunmuştur. Modele dahil edilen 23 açıklayıcı değişkenden 18 tane açıklayıcı değişken anlamlı bulunmuştur. Kişi başına düşen gelir tasarruf oranı üzerinde pozitif etkiye sahip olduğu görülmüştür. Tüketim kuramına ve literatüre göre gelir ile tasarruf oranı arasında pozitif ilişki söz konusudur (Edwards, 1995; Dayal-Ghulati veThimann, 1997; Loayza vd., 1999; Metin-Özcan ve Özcan, 2001). Tek kişilik hanelerde ve çocuksuz hanelerde tasarruf oranı çocuklu ailelere göre daha düşük eğilimlidir. Hanehalkı reisinin cinsiyeti tasarruf oranı üzerinde bir etkisi bulunmamıştır (Benzer sonuç Pan, 2016; Abdelkhalek ve ark.,2009 çalışmasında rastlanmıştır). Ancak kadın hanehalkı reislerinin tasarruf etme eğiliminde olacağı söylenebilir. Hanehalkı reisi çalışan hanelerde tasarruf yapma eğilimi yüksektir. Ekonomik politika açısından düşünüldüğünde istihdam artırıcı ve teşvik edici politikalar hanelerin tasarruf oranları üzerinde artırıcı etkisi olacağı sonucuna varıla bilinir. Benzer şekilde hanelerde çalışan kadın sayısının artması tasarruf oranını artırmaktadır. Bu sonuç ise kadın istihdamının istihdam politikaları açısından önemli olduğunu göstermektedir.

Hanedeki bağımlılık oranları yönünden genç bağımlılık oranı (0-14 yaş aralığındaki bireylerin hane büyüklüğüne oranı) tasarruf oranı üzerinde negatif bir etkiye sahiptir. Yaşlı bağımlılık oranı (65 yaş ve üzeri bireylerin hane büyüklüğüne oranı) ise tasarruf oranı üzerinde teorik beklentilerin aksine pozitif etkisi olduğu bulunmuştur (Benzer sonuçları Gondelman, 2014; Erdem, 2017 çalışmalarında görebiliriz.) Burada ortaya çıkan nokta Türkiye'nin kültürel yapısının ve yaşam şeklinin etkisinin olduğu söylenebilir. Hanelerde genç birey sayısı artması harcama kalemleri içerisinde eğitim ve sağlı masraflarının bu sonucu etkileyeceği düşünülmektedir. Oysa hanelerde yaşı birey sayısı artması ise bu bireylerin haneye katk1 sağladıkları ve ilave tasarruf yaptıkları düşünülebilir. Yaşam boyu gelir hipotezine göre bireylerin orta yaşlarda daha fazla tasarruf ettiğini söylerken ilerleyen yaşlarda negatif tasarruf yapacağı varsayımını bu çalışma kısmen sağlamaktadır. Hane reisinin yaşı 51-64 yaş arasında ise tasarruf oranı artarken 65 ve üstü yaş grubunda tasarruf oranı azalma göstermektedir. İlerleyen yaşlarda sağlık harcamalarının artmış olabileceği söylenir.

Hanehalkı reisinin eğitim düzeyi tasarruf oranı üzerinde negatif etkisi vardır. Özellikle eğitim düzeyi düşük hanehalkı reislerinin tasarruf eğilimleri azalmaktadır. Hanehalkı reisinin 
eğitim düzeyinin düşüklüğü çalışma koşularını, geliri ve harcamaları etkileyeceği için tasarruf eğilimini azaltacağı söylenebilir.

Hanelerin servet düzeylerinin tasarruf oranları üzerinde etkisine baktığımızda ise hanenin birinci konut sahipliği (hanelerin oturduğu konuta sahip olması) değişkeninin katsayısı pozitif olduğu bulunmuş. Oturduğu konuta sahip olan hanelerin kirada oturanlara göre harcama kaleminde yer alan kira bedelinden muaf olmaları tasarruf oranını beklendiği üzere artırmaktadır. İkinci konut sahipliği tasarruf oranı üzerinde etkisi yok iken arsa sahipliğinin tasarruf oranı üzerinde pozitif etkisi olduğu görülmüştür.

\section{Sonuç}

Ekonomide gelişmiş ve gelişmekte olan ülkeler için günümüz koşullarında ve ekonomik kriz süreçlerinde bireyler tüketim yapma ile birlikte tasarruf yapma kararları aşamasında dikkatli olmalıdır. Bireyler için tasarruf finansal açıdan hayatlarımızı güvence altına almak için, refah düzeyimizi yüksek tutabilmek için ve en önemlisi belirli bir yaşam standarttı elde edebilmek için önemlidir. Ülkeler için tasarruf ülkenin kalkınması için, yeni yatırımlar elde edebilmek için, yeni sermaye malları üretmek için, büyümede sürdürülebilirliği sağlamak için önemlidir (Oktayer, 2002).

Hanehalkı tasarrufları yıldan yıla değişkenlik göstermektedir. Türkiye için hanehalkı tasarruf oranı 2015 y1lında \% 13.5 iken 2017 y1lında \%15.1 ve 2018 y1lında ise \%13.9' gerilemiştir. Tasarruf oranındaki azalmanın nedeni olarak hanehalkı tüketimlerinin artmasını büyük etken olarak gösterile bilinir. Hanehalklarının tüketici kredilerine erişim imkanlarının artması ve kredi kullanımı ile birlikte tüketimin harcanabilir geliri aşmasından kaynaklandığı söylenebilir. Hanehalkı tasarruflarının belirleyicilerinin araştırılması ve tasarrufların artırılması için politika önerileri bulunmak açısından önemli bir konudur.

Bu çalışmada TÜİK-2018 HBA mikro veri seti kullanılarak hanehalkı tasarruf oranları üzerinde etkili temel faktörler literatür kapsamında incelenmiş ve buna uygun olarak değişkenler belirlenmiştir. Hanehalkı tasarruf oranlarına ilişkin araç değişken yöntemi kullanılarak tasarruf ile gelir arasındaki çift yönlü ilişki ele alınmıştır. Hanehalkı düzeyinde yapılan bu çalışmada gelir değişkenine ilişkin içsellik sorununu ortadan kaldıran uygun araç değişken seçilmiştir. Çalışmada analiz sonucuna göre temel bulgular doğrultusunda temel öneriler ortaya konmuştur.

Gelir düzeyinin artırılması ve gelir eşitsizliklerinin azaltılması tasarruf oranını artırmasına önemli ölçüde katkı sağlamaktadır. Bu süreçte işgücü niteliğinin ve verimliliğinin artırılması, eğitim seviyesinin artırılması tasarruf seviyesinde etkili olacağı kanısına varılmıştır. Hanelerde tasarruf oranını artırmak için belirli bir gelir seviyesine ulaşması gerekir. Hanehlkı reisinin işsiz 
olması tasarruf eğilimini azaltması hususunda ekonomik politika olarak istihdam artırıcı politikalar tasarruf oranını artırma üzerinde pozitif katkı sağlayacaktır. Özellikle hanelerde çalışan kadınların sayısının artırılması kadınların işgücüne katılımı istihdam politikalarının merkezinde olması tasarruf artırıcı politikalar arasında yer alması gerekmektedir. Oturulan konut sahipliği harcama kalemleri içerinde en yüksek paya sahip olan kira bedelinden muaf olunmasına ve tasarruf oranını artırmaktadır. Bireylerin tasarruf düzeylerini artırmak ülkelerin genel ekonomik yapılarına (gelir seviyesi, eğitim düzeyi gibi) bağlı olarak etkilenmektedir. Çalışmada kullanılan veri setinin 2018 HBA veri seti olması ve sonrası başka veri setinin olmaması önemli kısıtlarındandır. Hanehalkı tasarruf tercihlerini etki eden faktörleri daha iyi ortaya koyabilmek için veri setinin içeriğinin zenginleştirilmesi gerektiği düşünülmektedir. $\mathrm{Bu}$ konuda yapılacak sonraki çalışmalarda mevcut kısıtlamaların giderildiği veri seti ile tasarruf oranı üzerinde etkili faktörlerin tespit edilmesi önerilmektedir. 


\section{KAYNAKÇA}

Abdelkhalek, A., \& Freitas, N.M., \& Mage, S.A. (2009). "Microeconometric Analysis of Household Saving Determinants in Morocco",http://gdri.dreem.free.fr/wp-content/d21-arestoffetal_final.pdf (Çevirim içi, 7.10.2020).

Aka, K., \& Arıcan, E. “Türkiye’de Hanehalkı Tasarruf Davranışlarının Belirleyicileri”. Finansal, Araştırmalar ve Çalışmalar Dergisi, 11(21), 163-184.

Bagley, W.C. \& Perdew R.M., (1951). Understanding Economics, Macmillan.

Barış, S., \& Çiftçi, E. (2018). “Gelir Dağılımının Tasarruflar Üzerindeki Etkisi: Hanehalkı Düzeyinde Bir Araştırma”. ODÜ Sosyal Bilimler Araştırmaları Dergisi (ODÜSOBIAD), 8.1: 181-192

Baum, C., \& Mark, S., \& Steven S. (2003).’Instrumental Variables and GMM:Estimation and Testing”, Stata Journal, 3:1.

Barrett, N.S. (1975). The Theory of Macroeconomics Policy, Second Edition, Prentice Hall, INC., Englewood Cliffs, New Jersey, 1975.

Sipahi Beyaz F.B. (2020). "Hanehalkı Geliri ve Beden Kitle İndeksi Arasındaki İlişki: Araç Değişken Yaklaşımı”. ISPEC Journal of SocialSciences Humanities, 4(2), 77-97., Doi: 10.46291/ISPECIJSSHvol4iss2pp7797 (Yayın No: 6234460).

Bozkuş, Ş., \& Üçdoğruk Ş. (2007). "Hanehalkı Tasarruf Tercihleri Türkiye Örneği”. 8. Türkiye Ekonometri ve İstatistik Kongresi, Malatya, 24-25 Mayıs 2007.

Browning, M. (1995). "Saving and The Intra-Household Distribution Of Income: An Empirical Investigation". Ricerche Economiche, 49(3), 277-292.

Cameron, A.C. \& Trivedi, P.K. (2009). Microeconometrics Using Stata, Published by Stata Press, College Station, Texas, 171-204.

Chen X., \& Li R., \& Wu X.(2019).” Multi-home Ownership and Household Portfolio Choice in Urban China”. Journal of Housing and the Built Environment. https://doi.org/10.1007/s10901-019-09713-8

Collins, S.M. (1989). "Saving Behavior in Ten Developing Countries". Paper presented at the NBER Conference on Savings, Maui (Cambridge, Massachusetts: National Bureau of Economic Research).

Çolak,Ö.F. \& Öztürkler, H. (1997). "Tasarrufun Belirleyicileri: Küresel Tasarruf Eğilimindeki Değişim ve Türkiye'de Hanehalk1 Tasarruf Eğiliminin Analizi”. Bankacılar Dergisi, No.2012/82, 2012, pp.3-44.

Dayal-Gulati, A. \& Thimann, C. (1997). "Saving in Southeast Asia and Latin America Compared: Searching for Policy Lessons". IMF Working Paper, Say1:97.

Edwards, S. (1995). "Why are Saving Rates So Different Across Countries? An International

Comparative Analysis". NBER Working Paper, 5097 (Cambridge, Massachusetts: National Bureau of Economic Research).

Erdem P.B. (2017).’Türkiye'de Hanehalkı Tasarruflarını Etkileyen Faktörler”. Ekonomik Modeller ve Stratejik Araştırmalar Genel Müdürlüğ̈̈, Ankara.

Gandelman,N. (2014).“A Comparison of Saving Rates: Micro Evidence from Nine Latin American Countries”. IDB Working Paper Series, 2014.

Gujarati D.N., \&VPorter D.C. (2009). Basic Econometrics, Fifty Edition, Singapore,

Hamarat,B., \& Özen, E. (2015).“Türkiye'de Tasarruf Tercihlerini Etkileyen Değişkenlerin Kanonik Korelasyon Analizi İle Belirlenmesi”. Journal of Life Economics cilt:2, No:1.p:47-74.

Kostakis,I. (2013). "The Determinants of Households' Savings During Recession: Evidence from Greece" Available at SSRN: https://ssrn.com/abstract=2323559 or http://dx.doi.org/10.2139/ssrn.2323559.

Loayza,N., \& Schmidt-Hebbel, N.K., Serven, L. (2000). "Saving in Developing Countries: An Overview". The World Bank Economic Review, Vol.14, No.3, pp.393-414.

Mankiw,N.G. (1992). Macroeconomics, Worth Publishers, New York.

Mc-Connell, C., \& Campbell R., Brue S. (2008). Macroeconomics: Principles, Problems, and Policies. 17.Bask1, ABD: McGraw-Hill, 2008.

Metin-Özcan, K., \& Voyvoda, E., \& Yeldan, A.E. (2001). "Dynamics of Macroeconomics Adjustment in a Globalized Developing Economy: Growth, Accumulation and Distribution, Turkey 1969-1999". CanadianJournalofDevelopmentStudies, 22, 219-53.

Modigliani, F. (1986). "Life Cycle, Individual Thrift, and the Wealth of Nations". American Economic Review, 76, 297-313.

Narinç,N.Ö., \& Küçükönder,H., (2020). "Hanehalkı Tasarruf Tercihlerinin Ardışık Logit Modelle Belirlenmesi: Türkiye Örneği’. İşletme Araştırma Dergisi. 12(2). 1554-1572.

Oktayer,N. (2002). “Gelir ve Tüketim Vergilerinin Tasarruf Üzerine Etkileri”. İstanbul Üniversitesi İktisat Bölümü, Maliye Araştırma Merkezi Konferanslarl 41.Seri.

Pan, Y.( 2016). "Understanding the Rural and Urban Household Saving Rise in China. Regional”. Science and Urban Economics, 56,p:46-59

Rehman, H., \& Bashir F., \& Faridi, M. (2011). "Saving Behavior among Different Income Groups in Pakistan: A Micro Study”. International Journal of Humanities and Social Science, 1:10. 268-277. 
Rijckeghem,C.V. (2010). "Determinat of Private Saving in Turkey: An Uptade”. Boğaziçi Üniversitesi İktisat Bölümü Çalışma Tebliği, No.4.

Sachs, J.D., \& Larrin, B. (1993). Macroeconomics in The Global Economy, Prentice Hall, INC., New Jersey.

Şengür, Y., \& Taban, P. (2016). “Gelir Dağılımı-Tasarruf İlişkisi: Türkiye'de Hanehalkı Gelir Türünün Tasarruflar Üzerindeki Etkisi”. Anadolu Üniversitesi Sosyal Bilimler Dergisi, 16 (1) 49-71.

Temel Nalın, H. (2013). "Determinants of Household Saving and Portfolio Choice Behaviour in Turkey". Acta Oeconomica, 63(3), 309-331.

Tobin, J. (1967). "Life Cycle Saving and Balanced Growth". in William Fellner, ed., Ten Economic Studies in the Tradition of Irving Fisher, John Wiley, pp. 231-56.

Tunalı, H., \& Tatoğlu, F.Y. (2010). "The Analysis of Factors Affecting Investment Choices of Households inTurkey with Multinomial Logit Model”. International Research Journal of Finance and Economics, 40.

Türkiye İstatistik Kurumu (TÜİK), Hanehalkı Bütçe Anketleri (2018), Ankara.

Ünsal, E.M.(2005).Makro İktisat, 6. Baskı, İmaj Yayıncılık, Ankara. 